\begin{tabular}{ll}
\hline \hline MINING AND METALLURGY INSTITUTE BOR & ISSN: 2334-8836 (Štampano izdanje) \\
UDK: 622 & ISSN: 2406-1395 (Online) \\
\hline \hline
\end{tabular}

\author{
Georgi Dachev", Kiril Kutsarov*
}

\title{
METHODOLOGY FOR ASSESSMENT AND ANALYSIS \\ THE GEOMECHANICAL STATE OF THE OPENCAST MINING OPERATIONS BUILT UP IN THE ROCK MASSES
}

\begin{abstract}
Ensuring the stability of constructive elements (rock flanks or benches) in the opencast pits and quarries is carried out in a different way, and this is often the reason of considering only separate parameters to be taken. Such assessments are often made using the different hypotheses and formulae such as those of Tsimbarevich, Fellenius, Maslov, Fisenko, etc. The key factors, influencing such assessments together and separately, are numerous and in most cases it is difficult to gather them together with one summarized formula. This paper presents a structured uniform methodology in order to provide an approach for assessment targeting the geomechanical state of the opencast mining operations, situated in the homogeneous rock masses.
\end{abstract}

Keywords: methodology for assessing the stability, rock masses, geomechanical state parameters

\section{INTRODUCTION}

The technological and operation processes of the excavation - loading mechanization and working mining specialists in the opencast pits and quarries are related to ensuring the stability of structural elements (flanks and benches). The pursuit of mining engineers to achieve higher heights and widths of the benches very often results in deformations and subsequent slides (collapses) along these structural elements, stopping or discontinuing the work processes or blocking the entire parts of the mining site.

To determine the geomechanical condition of the structural elements under consideration, terms as stable/unstable are used, whereas the boundary between the two is not fully quantified. There is also no uniform methodology in applying the computational procedures, and in most cases, only one formula or one model is used, which often is not even calibrated.

The well-known formulae and methods for assessment the stability of flanks, slopes and benches are those of Tsimbarevich, Fellenius, Maslov, Fisenko, Terzagi, Froelich and many others. All formulae and methods only give separate components of the state and properties of the rock mass, rather than assessing them as a whole. When assessment the geomechanical state of a rock slope, no account is taken on orientation, joint length, distance and type of filling substance of the joints. For example, in assessment the stability of a slope made up of marl, the mass strength - "in situ", its natural humidity, stratified structure, etc. are not taken into account.

Bulgaria has introduced the requirement that the mining and primary processing pro-

\footnotetext{
* Univesrity of Mining and Geology St. Ivan Rilski, Department of Underground Mining, Rock Mechanics and Geomechanics, Prof. Bojan Kamenov Street No. 1, 1700 Sofia, Bulgaria, e-mail: georgidachev87@gmail.com: kbkutsarov@gmail.com
} 
jects for the underground natural resources should include sections on geomechanics and rock pressure management with Ordinance [11] in force since 2016. These sections should demonstrate the stability of design and existing opencast mining works and measures to prevent the negative geodynamic processes.

Ensuring the stability of mining works has always been and should be a leading condition when choosing the parameters for the method of mining, but in recent years there has been a disparaging attitude to this important issue. The relevant sections in the work projects are also developed mainly by the non-specialists in the field of geomechanics and are only intended to meet the mandatory provisions of the above-mentioned ordinance, instead of providing the real data on the rock mass state and choosing the adequate parameters for the method of mining, respectively.

Because of all these issues, a uniform solution, grounded on the real state parameters in order to identify separate and mutually influencing factors, should be found.

\section{FACTOR OF STABILITY (SAFETY)}

Defining the factor of safety (FS) for the rock mass state is a multi-complex approach that has to follow certain criteria. A number of mining specialists and scientists define in different ranges the factor of safety the slopes and benches of the opencast pits and quarries. Some of them (Fisenko, Arseniyev, Maslov) consider the FS of a bench or slope to be when the rock mass counteracts the external forces; the rock mass maintains its integrity and state for an extended period of time. Others believe that the FS is the state when the ratio of sliding forces to the retaining forces is more than one. Because of these and other factors, it is necessary to define when a structural element is stable and will break its integrity. This is possible thanks to the assessment methodology that systematizes in a single assessment all the factors influencing the stability and answers the question what is stable and what is unstable. In Bulgaria, according to the Ordinance No. 12/03.07.2001 and Euro Code 7, under the basic combination of load, the minimum factor of stability (also known as the factor of safety) must satisfy the condition: $\mathrm{FS} \geq 1.25$.

\section{ASSESSMENT METHODOLOGY}

It is well known that each individual case for assessing the state of structural elements (slopes and benches) requires an individual approach that meets the specifics of the mining site. This is necessitated by the rock mass lithology, its momentary state and/or its structural disturbance. For this purpose, we have proposed a uniform methodology presented in Figure 1.

The methodology for assessing the stability of opencast mining workings localized in homogeneous rock masses uses the so-called state parameters (databases) that can be determined (laboratory and/or "in situ"). In this sequence, both general slopes and individual benches can be dimensioned. The lack of a database for the composition and the structural characteristics of the rock mass has led to a number of laboratory tests following the ISRM [5] recommendations that have been used over the past thirty years.

The presented methodology can be implemented taking into consideration the influence of density and strength - deformation parameters, structural characteristics and their interaction, which can ensure the stability and corresponding effectiveness and safety during mining. This database requires a preliminary assessment related to the review of available information, hydrogeological conditions, geology, composition, etc. for the production level or section where the dimensioning or assessment the slope/bench will be carried out. In order to accomplish and acquire the necessary database, it is necessary to get acquainted in advance "ïnsitu" with the location and orientation the various lithological varieties of rocks. It is 
also necessary to provide the information on structural disturbance both in terms of surface area and height. It is necessary to know that the "in-situ" research studies also be in line with the recommendations of the ISRM [5].

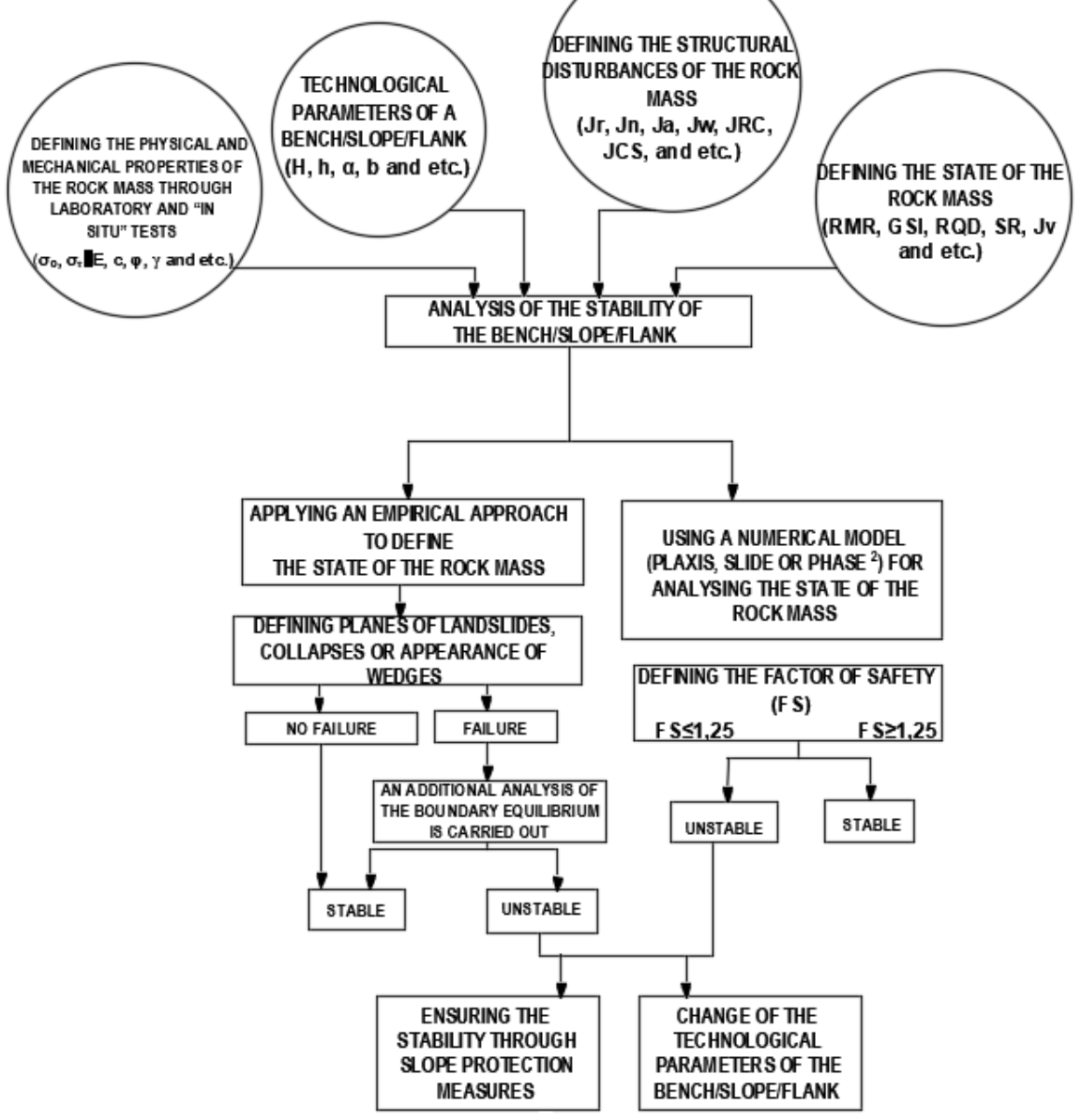

Figure 1 Methodology for geomechanical assessment

The next step of methodology reflects the dimensioning by means of empirical or numerical methods. When choosing a modeling method, it is necessary first to formulate a model reflecting the geomechanical and structural characteristics. The widely used models on the basis of the methods of finite, boundary elements or currently, hybrid methods for solving such tasks are also widely used.
The third important stage of methodology is the determination of load (sliding forces) $(\sigma)$ and retaining forces $(\mathrm{S})$ after specifying the geometric parameters of the bench. Based on these two factors, the safety factor (FS or FOS) is assessed. The method preferred most for the geomechanical assessment is the "Boundary Element Method". 
The boundary states are grouped into the sets, symbolically shown in Figure 2.

The most appropriate method is found to be the GEO:

- GEO states - strength failure (including as a result of inadmissible deformations) of the ground, related to the disturbance of relative and overall stability (bearing capacity) of the rock mass under foundations (flat, pilot, well or mixed type foundations); strength failure in the rock masses resulting from the sliding of parts of it, etc. or generally, failures in the ground base under loads or when its stressed state is changed.

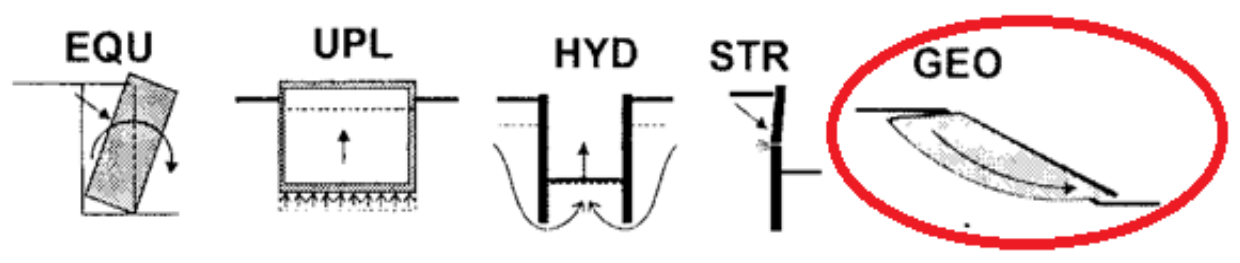

Figure 2 Sets of boundary states

- In the GEO equilibrium state, the following condition has to be observed: $\mathrm{Ed} \leq \mathrm{Rd}$.

Ed - active force resulting from external and internal loads (impacts), called the computational value of impact. Rd - maximum resistance force, strength, called the computational value of strength or bearing capacity.

To determine $\mathrm{Rd}$, the combined methods are used applying the different combinations of impacts, and computational geotechnical properties of the varieties are only determined by the laboratory tests.

Most importantly, the proposed assessment methodology can also be used in assessment the state of underground mining portals such as tunnels and entrances of adits and inclined shafts built into rock masses as it includes a wide range of data characterizing the state of such important facilities.

\section{APPLICATION OF METHODOLOGY}

The methodology has been verified and applied to assess the geomechanical state of slopes and benches in the limestone quarries. The research has been carried out for a quarry that produces limestone as a major lithological variety of rocks. It should be noted that this was done following the proposed sequence of operations presented in Fig. 1 such as: the studies started with the structural disturbance of rock mass both in terms of surface area and height, then the strength-deformation properties of rock mass samples were determined and, as a final result, the structural state and quality of studied section were reported.

The studies started with in situ and laboratory methods to determine the physical and mechanical properties of the bedding rock mass. These studies include determining the strength (c, $\varphi, \sigma_{\mathrm{c}}, \sigma_{\mathrm{t}}, \tau_{\mathrm{cp},}$ etc.), density $\left(\gamma, \rho, w_{i}\right.$, etc. $)$ and deformation $\left(\left(E_{e l}\right.\right.$, $E_{\text {def. }}, v$, etc.) parameters. The tests were performed according to the established ISRM procedures [5]. It should be also noted that the RocData program [10] was used to obtain the values of individual parameters presented in Table 1, which characterize the strength-deformation properties of the rock mass. 
Table 1 Laboratory results for the physical and mechanical properties of the bedding rock mass

\begin{tabular}{|c|c|c|c|c|c|c|c|}
\hline Parameter & $\begin{array}{c}\text { In situ } \\
\text { density } \\
\gamma, \\
{\left[\mathrm{MN} / \mathrm{m}^{3}\right]}\end{array}$ & $\begin{array}{l}\text { Uniaxial com- } \\
\text { pressive } \\
\text { strength, } \sigma \text { ucs } \\
\text { [MPa] } \\
\text { min/max }\end{array}$ & $\begin{array}{c}\text { Tensile } \\
\text { strength, } \\
\text { ot [MPa] } \\
\text { min/max }\end{array}$ & $\begin{array}{c}\text { Cohesion } \\
\text { C cp. } \\
\text { [MPa] }\end{array}$ & $\begin{array}{c}\text { Internal } \\
\text { friction } \\
\text { angle } \varphi \\
\text { cp., }\left[^{\circ}\right]\end{array}$ & $\begin{array}{c}\text { Elasticity } \\
\text { modulus, } \\
\mathrm{E}[\mathrm{MPa}] \\
\mathrm{min} / \mathrm{max}\end{array}$ & $\begin{array}{c}\text { Poisson's } \\
\text { ratio v } \\
\text { average. }\end{array}$ \\
\hline Limestone & 0.0267 & $45.8 / 68.5$ & $12.2 / 16.7$ & 6.1 & 38.4 & $\begin{array}{c}39650 / \\
58370\end{array}$ & 0.22 \\
\hline
\end{tabular}

In details, for assessment the rock mass state, which builds a slope in the end contour, the "in situ" methods were used and the following parameters were defined: distance between the disturbances Rdj, joint length of disturbances L, type of the joint (x, r or d), orientation of the joint Roj, roughness of the joint Jr (rough, smooth, wind-polished, etc.), degree of joint weathering (fresh, slightly weathered, moderately weathered, high weathering, etc.), determining the joint wall compressive strength (JCS), determining the joint opening (open, moderate, wide, etc.), disturbance saturation Jw (dry, moist, wet, etc.).

For the analysis of results, the Barton standardized rocks [5] were used to determine the joint roughness (JRC) and wall strength (JCS), presented in Figure 3.

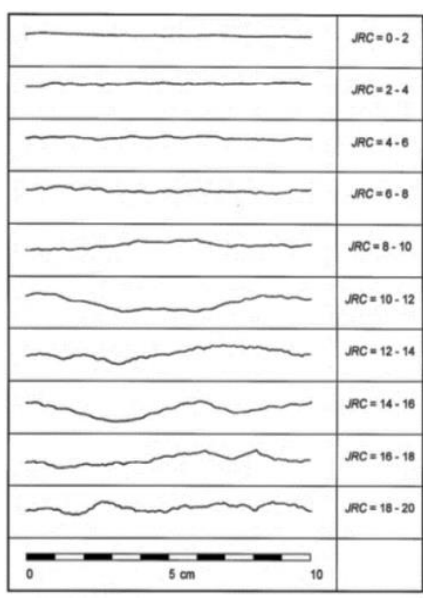

A)

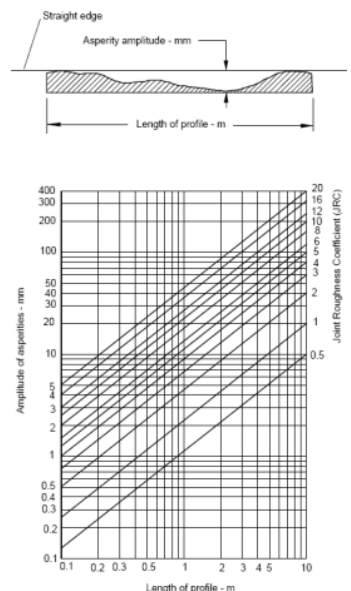

B)

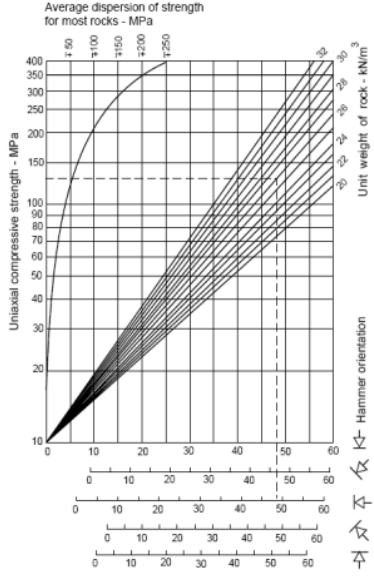

C)

Figure 3 Additional Barton's graphs for defining the assessments JRC (A and B) and JCS (C)

For the analysis of geomechanical state of the rock mass using the obtained results in the analyzed profile, the geomechanical classification RMR (Rock Mass
Rating, according to Bieniawski [6], was applied. The results from the qualification assessment are presented in Table 2. 
Table 2 Results from the qualification assessment RMR (Bieniawski 1989).

\begin{tabular}{|c|c|}
\hline Qualification assessment_ Parameter & $\begin{array}{c}\text { Rock Mass Rating } \\
\text { (RMR) }\end{array}$ \\
\hline R $\beta \mathrm{s}$ & 7 \\
\hline $\mathrm{R}_{\mathrm{RQD}}$ & 13 \\
\hline Rdj & 20 \\
\hline Rci & 20 \\
\hline Rwi & 15 \\
\hline Roj & -5 \\
\hline RMR & $\mathbf{7 0}$ \\
\hline
\end{tabular}

The obtained results show that the rock mass falls into the second class according to the Benyanski classification, i.e. it is of good quality. The RMR assessment gives a possibility to determine the geological strength index GSI: GSI $=\mathrm{RMR}_{89^{-}}-5 \rightarrow$ $\mathrm{GSI}=65$.

The results providing a relationship between the structural disturbances and state of the rock mass [1] are presented in Table 3.

Table 3 Results providing the relationship between the structural disturbances and rock mass state with the help of the GSI (Hoek and Brown 1998)

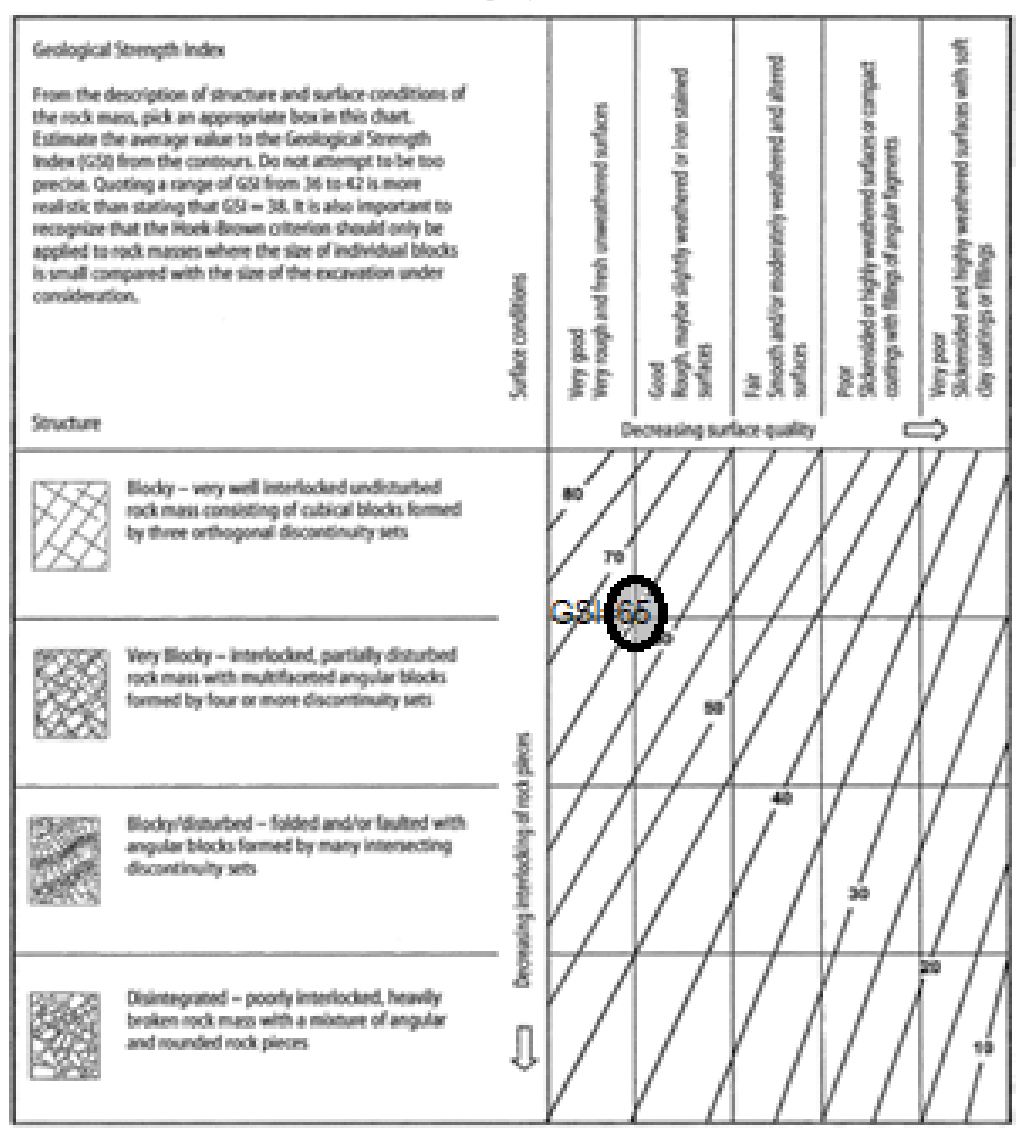


Table 4 presents the results for the GSI defined by the Sonmez and Ulusay [4] graph, they allow verification of the re- sults determined using the RMR classification rating.

Table 4 Defining the GSI values using the Sonmez and Ulusay graph

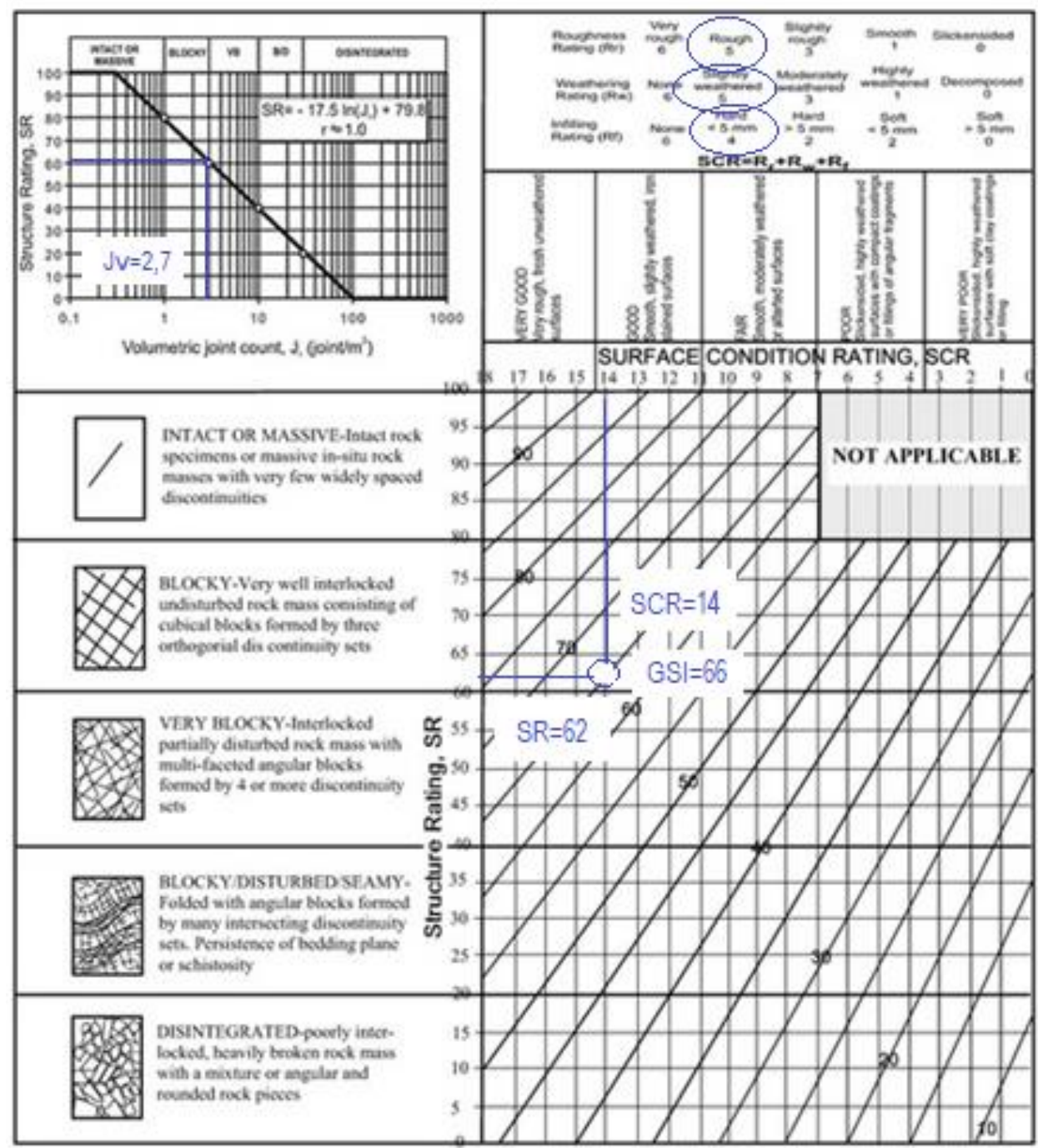

The results obtained in Table 4 make it possible to link the in-situ index of fissuration, geological strength index and surface state of the disturbances by their assessment. The obtained results in Table 4 also allow verification of the GSI results, ob tained by the classical method, in orde to adequately set it as an input parameter in the numerical model.

The final step for obtaining the input information involves accurate measuring the geometric parameters of analyzed profile 
(heights, widths, angle of inclination, etc.) using the geodetic methods. This measurement includes a detailed determination the height of analyzed profile of a flank $(\mathrm{H})$, general angle of a slope (b), flank profile type, inclination angle of a bench (a), bench height (h), bench width (b), etc.

Following the proposed methodology (Figure 1), the existing database is used to develop an adequate model and its accompanying stability analysis using the numerical software $[8,9]$ presented in Figure 4. The model in Figure 4 includes a high wall composed of five benches in the eastern section of the limestone quarry, covering the five levels in height - from the level 185 to the level 260.
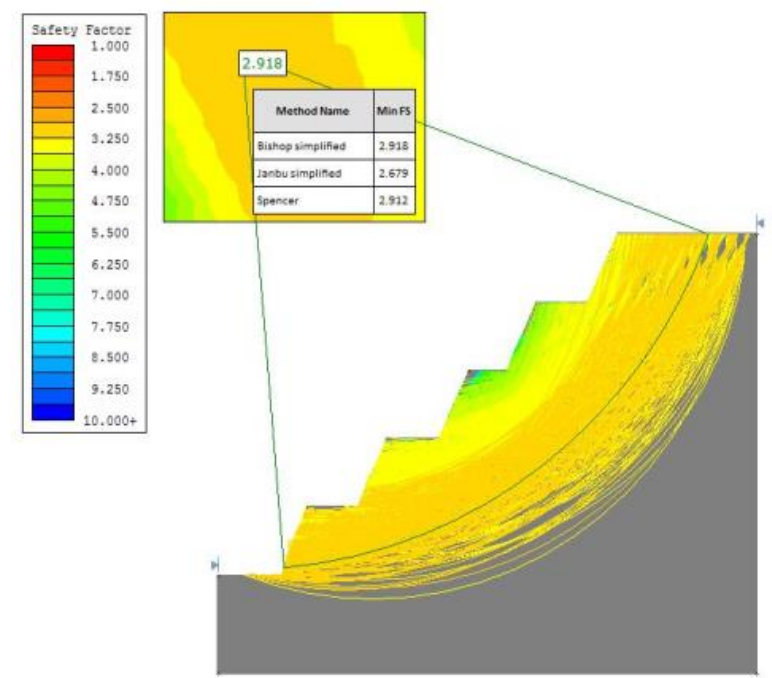

A)
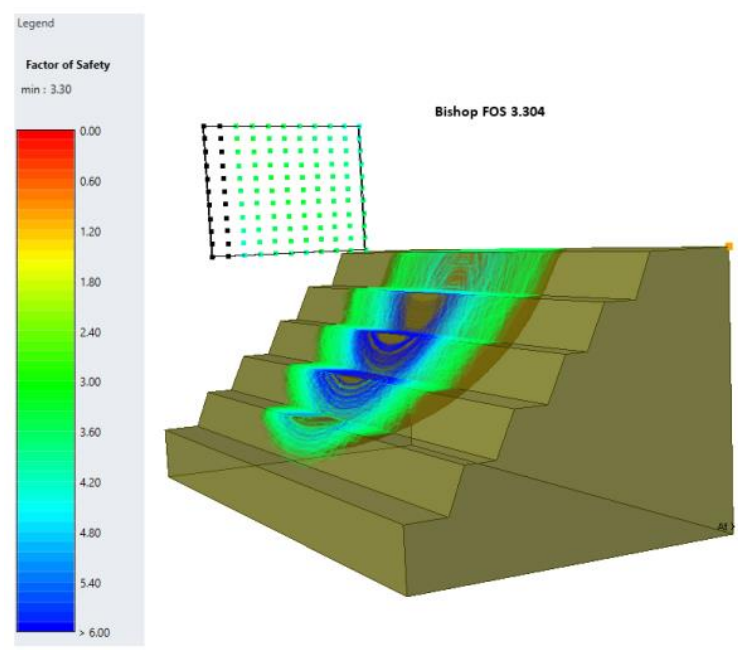

B)

Figure 4 Stability calculations for a high wall built in a rock mass using a two-dimensional model Slide 7.0 - A; using a three-dimensional model Slide 32017 - B 
The software products of the Canadian company Rocscience [8, 9] allow the boundary state calculation by several methods. The methods of Bishop, Janbu and Spencer were used for the stability calculation of a flank. The software allows many of in-situ and laboratory evaluations, defined as the database, to be set as the input parameters. In addition, they allow the identification of landslide surface or local losses of stability.

For the example under consideration, no dangerous sliding surfaces have been reported under the three methods of analysis. Similarly, in the three methods, the safety factor is significantly higher than the normative minimum; the results for both numerical models are almost the same, which means that the model works adequately. The analysis shows that no sliding surfaces that disrupt the local stability have been identified in any of the five benches building up a flank, as well as no wedges have been formed which can lead to sliding.

For a more complete and accurate verification of the obtained results, it is advisable to use the left-hand branch of methodology applying the empirical methods of analysis. This allows the final design solution to be justified by the two independent methods using the same input parameters.

\section{CONCLUSION}

The need for adequate stability analyses requires the development of a new methodology for complex parametric, geomechanical assessment and logistics. The purpose of methodology is to serve in the assessment of stability and preliminary dimensioning of flanks, slopes and benches at the opencast mining sites. Following the proposed methodology, it allows the accurate engineering solutions to determine the state and stabilityof structural elements at the open pit mines and quarries.

The applicability of assessment and analysis methodology is indisputable due to the fact that it has been applied and verified in practical conditions in assessment the geomechanical status of a high wall in a rock mass made up of limestone. The results from these studies were subsequently introduced into the production process.

\section{REFERENCES}

[1] Hoek E. Brown E. T. Practical estimates of rock strength. Int. J of RM and Min. Sci. 37, 1997.

[2] Hoek E. Bray J.R. Rock slope engineering. London Institution of Mining, p 3581981 .

[3] Ulusay R., Hudsun J. A. The complete ISRM suggested methods for rock characterization testing and monitoring 1974-2006.

[4] Sonmez H., Ulusay R. Modifications to the geological strength index (GSI) and their applicability to stability of slopes. Int. J of RM and Min. Sci. (36), 743-760 1999.

[5] ISRM Suggested Methods. Rock Characterisation Testing and Monitoring. Pergamon, Press, 1981.

[6] Bieniawski Z. T., Engineering Rock Mass Classifications: a Complete Manual for Engineers and Geologist in Mining, Civil, and Petroleum Engineering. John Wiley\&Sons. New York /Chichester/Brisbane/Toronto/Singapo re. 1989.

[7] Kochkar M.K. et al. Methodology for tunnel and portal support design in mixed limestone, schist and phyllite conditions: a case study in Turkey, Int. J of RM and Min. Sci. 40, 2003. 
[8] Rocscience Slide ver. 7.0. Rocscience, Toronto, Canada 2016.

[9] Rocscience Slide 3 ver. 1.0.

Rocscience, Toronto, Canada 2017.

[10] Rocscience, RocData ver. 5.0. Rocscience, Toronto, Canada 2016.

[11] Ordinance on the requirements for the scope and content of the working projects for prospecting and exploration or for exploration, extraction and primary processing of underground natural resources, for the liquidation and / or conservation of the geological prospecting and mining sites and for the reclamation of the affected lands and for the conditions and the order for their reconciliation (Adopted with the Act of the Council of Ministers N248/25.10.2013, State Gazette, $\mathrm{N} 95 / 1.11 .2013$, in force as of 1.11.2013, amended, N5/19.01.2016, in force as of 19.01.2016). 